OPEN ACCESS

Edited by:

Tony D. James,

University of Bath, United Kingdom

Reviewed by:

Lin Yuan,

Hunan University, China

Yuya Egawa,

Josai University, Japan

David C. Magri,

University of Malta, Malta

*Correspondence:

Takashi Hayashita

ta-hayas@sophia.ac.jp

Specialty section: This article was submitted to

Supramolecular Chemistry,

a section of the journal

Frontiers in Chemistry

Received: 30 September 2019 Accepted: 08 November 2019

Published: 27 November 2019

Citation:

Sugita K, Tsuchido Y, Kasahara C, Casulli MA, Fujiwara S, Hashimoto T

and Hayashita $T$ (2019) Selective

Sugar Recognition by

Anthracene-Type Boronic Acid

Fluorophore/Cyclodextrin

Supramolecular Complex Under

Physiological pH Condition.

Front. Chem. 7:806.

doi: 10.3389/fchem.2019.00806

\section{Selective Sugar Recognition by Anthracene-Type Boronic Acid Fluorophore/Cyclodextrin Supramolecular Complex Under Physiological pH Condition}

\author{
Ko Sugita ${ }^{1}$, Yuji Tsuchido ${ }^{1,2}$, Chisato Kasahara ${ }^{1}$, Maria Antonietta Casulli ${ }^{1}$, \\ Shoji Fujiwara ${ }^{1,3}$, Takeshi Hashimoto ${ }^{1}$ and Takashi Hayashita ${ }^{1 *}$
}

${ }^{1}$ Department of Materials and Life Sciences, Faculty of Science and Technology, Sophia University, Tokyo, Japan, ${ }^{2}$ Department of Life Science and Medical Bioscience, Graduate School of Advanced Science and Engineering, Waseda University (TWIns), Tokyo, Japan, ${ }^{3}$ Department of Current Legal Studies, Faculty of Law, Meiji Gakuin University, Yokohama, Japan

We synthesized novel PET (photoinduced electron transfer)-type fluorescence glucose probe 1 [(4-(anthracen-2-yl-carbamoyl)-3-fluorophenyl)boronic acid], which has a phenylboronic acid (PBA) moiety as the recognition site and anthracene as the fluorescent part. Although the PBA derivatives dissociate and bind with sugar in the basic condition, our new fluorescent probe can recognize sugars in the physiological $\mathrm{pH}$ by introducing an electron-withdrawing fluorine group into the PBA moiety. As a result, the $\mathrm{pK} \mathrm{K}_{\mathrm{a}}$ value of this fluorescent probe was lowered and the probe was able to recognize sugars at the physiological $\mathrm{pH}$ of 7.4 . The sensor was found to produce two types of fluorescent signals, monomer fluorescence and dimer fluorescence, by forming a supramolecular 2:1 complex of $\mathbf{1}$ with glucose inside a $\gamma$-cyclodextrin $(\gamma$-CyD) cavity. Selective ratiometric sensing of glucose by the $1 / \gamma$-CyD complex was achieved in water at physiological $\mathrm{pH}$.

Keywords: cyclodextrin, boronic acid, supramolecular chemistry, fluorescence, sugar recognition

\section{INTRODUCTION}

Sugars, especially monosaccharides, play important roles in various biological systems (Brewer et al., 2002; Davis, 2002; Brodesser et al., 2003). There are many types of monosaccharides, such as glucose, galactose, fructose, etc., and their roles or abundance ratios in vivo are different. However, their molecular weights are identical, and each monosaccharide has various steric conformations in water. These facts have made their identification by molecular recognition difficult. Selective sugar recognition has captured the interest of disease, cancer, medical care, or food chemistry researchers (Ohtsubo and Marth, 2006; Jin et al., 2010; Xu et al., 2013). The conventional glucose sensor is an enzyme-type sensor that uses glucose oxidase (GOx) and enables the highly selective and quantitative analysis of glucose in the physiological condition (Sierra et al., 1997; White and Harmon, 2002; Endo et al., 2006; Kanekiyo and Tao, 2006; Ekanayake et al., 2007; Ye et al., 2010; Sun and James, 2015). However, the enzyme method is expensive and unstable due to denaturation. Therefore, the development of a stable non-enzyme-type chemical (artificial) glucose sensor is in great demand. 
Over the past several decades, the development of sugar recognition molecules using phenylboronic acid (PBA) has been widely conducted (James et al., 1996; Kanekiyo and Hiraoki, 2005; Anslyn, 2007; Egawa et al., 2007, 2009; Fujita et al., 2008; Minami et al., 2014; Iwami et al., 2015; Tsuchido et al., 2015, 2016, 2017; Zhai et al., 2015; Shimomura et al., 2016; Wu et al., 2016, 2017; Nishiyabu et al., 2018). PBA is known to form cyclic boronate ester with the cis-diol group in the sugar. There are many reports of glucose sensors using PBA. Examples include colorimetric-type sensors that are based on absorption spectrum shift (Egawa et al., 2007, 2009), excimer fluorescence-type sensors (Kanekiyo and Hiraoki, 2005), micellar-type sensors that are based on hydrophobic interaction (Tsuchido et al., 2016; Wu et al., 2016), and near-infrared fluorescence-type sensors (JoSaiRed) (Shimomura et al., 2016).

Our research group has developed pyrene-type, anthracenetype, and naphthalene-type sugar recognition fluorescent PBA sensors (Ozawa et al., 2008; Kumai et al., 2012; Kano et al., 2014; Soma et al., 2018; Hashimoto et al., 2019), all of which are photoinduced electron transfer (PET)-type sensors. When these sensors bind with sugar, fluorescence emission by PET inhibition between the fused ring and the PBA moiety takes place. A unique phosphate anion sensor based on the macrocyclic boron complex at PBA-anthracene probe using PET mechanism was reported by Kameta and Hiratani (2006). However, anthracene and pyrene are highly hydrophobic and show poor solubility in water. Cyclodextrin $(\mathrm{CyD})$ is an efficient host molecule that is able to incorporate various organic molecules in water. As a hydrophobic sensor (or probe) is included inside the CyD cavity, the formation of a stable supramolecular complex in water is expected.

This supramolecular inclusion system has several merits: (1) fluorescence emission can be enhanced by the formation of an inclusion complex of the fluorescent moiety and the hydrophobic CyD cavity; (2) selective glucose recognition can be expected by the 2:1 binding of PBA with glucose inside the CyD cavity; and (3) selective dimer fluorescence can be expected by the dimer formation of fluorophores, realizing ratiometric analysis. Generally, it is difficult to achieve glucose selectivity in a 1:1 binding system because PBA has a high binding constant for fructose compared to that for glucose. In contrast, the multipoint recognition-type sugar sensor having two (or more) PBA recognition sites is known to realize glucose selectivity by forming a 2:1 complex with glucose (James et al., 1994).

Recently, we have shown an efficient dimer formation for selective glucose sensing, in which two fluorescent molecules are included inside a CyD cavity and emits dimer fluorescence at long wavelengths (Hashimoto et al., 2019). However, this system realizes glucose recognition only in the basic condition $(\mathrm{pH} 11)$ due to the high $\mathrm{p} K_{\mathrm{a}}$ value of PBA. Coordination of hydroxide to PBA to form tetrahedral boronate occurs only in the basic condition $(>\mathrm{pH} 9)$. Thus, the sugar recognition function is usually evaluated in the basic condition $(>\mathrm{pH} 9)$, as shown in previous reports using PBA sensors.

In this study, we introduced an electron-withdrawing fluorine group into the phenyl group of the PBA moiety to reduce the $\mathrm{p} K_{\mathrm{a}}$ value of PBA (Figure 1). Several articles have reported

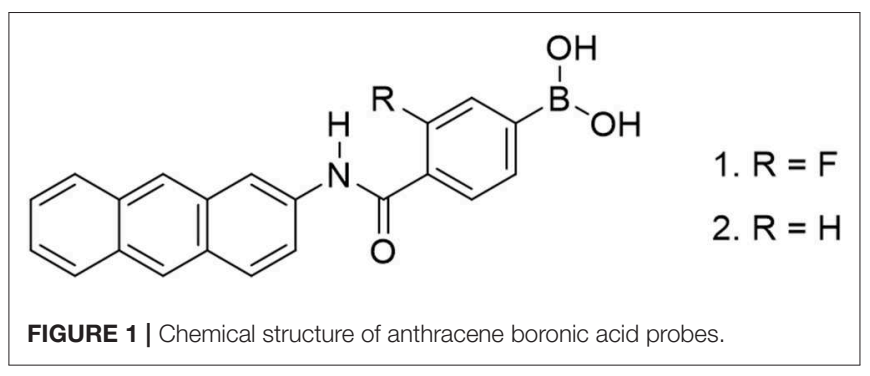

the introduction of fluorine into PBA (Shoji and Freund, 2002; Deorea and Freund, 2003; Matsumoto et al., 2013), but there are no reports of supramolecular CyD-inclusion complex systems. Herein we report the introduction of fluorine into $\mathrm{PBA}$ to reduce the $\mathrm{p} K_{\mathrm{a}}$ value of the probe, and selective glucose sensing at physiological $\mathrm{pH}$ in water, by measurements of fluorescence spectra and induced circular dichroism (ICD) spectra.

\section{EXPERIMENTAL SECTION}

\section{Apparatus}

Fluorescence spectra were measured with a Hitachi F7000 fluorescence spectrometer equipped with a Peltier thermocontroller (Hitachi High-Tech Science Co., Tokyo, Japan) and a $1.0-\mathrm{cm}$ quartz cell. Fluorescence emission from 350 to $600 \mathrm{~nm}$ was monitored at the excitation wavelength of $323 \mathrm{~nm}$ with a $2.5-\mathrm{nm}$ slit width. UV-vis spectra were measured with JASCO V-570 and JASCO V-560 UV-vis spectrophotometers equipped with a Peltier thermocontroller (JASCO Co., Tokyo, Japan) and a $1.0-\mathrm{cm}$ quartz cell. Circular dichroism (CD) spectra were recorded with a JASCO J-820 spectrophotometer equipped with a Peltier thermocontroller (JASCO Co., Tokyo, Japan) and a 1.0-cm quartz cell. ${ }^{1} \mathrm{H}$ NMR spectra were obtained with a JEOL JNM-ECX 300 spectrometer or a JEOL JNMECA 500 spectrometer (JEOL Ltd., Tokyo, Japan) at $300 \mathrm{~K}$. Elemental analysis was performed using a PerkinElmer 2400 Series II CHNS/O Elemental Analyzer (PerkinElmer, Inc., MA, USA). ESI-MS spectra were recorded on a JEOL JMST100LC instrument (JEOL Ltd., Tokyo, Japan). All synthetic reactions were monitored by thin-layer chromatography (TLC) on silica gel $60 \mathrm{~F}_{254}$ plates (Merck). All $\mathrm{pH}$ values were recorded with a Horiba F-52 pH meter (HORIBA Ltd., Kyoto, Japan).

\section{Reagent and Chemicals}

4-Carboxy-3-fluorophenylboronic acid, pinacol, 4-(4,6dimethoxy-1,3,5-triazin-2-yl)-4-methylmorpholinium chloride $n$-hydrate (DMT-MM), tetrahydrofuran, hydrochloric acid, sodium hydroxide, $\beta$-cyclodextrin, $\gamma$-cyclodextrin, fructose, glucose, galactose, phosphoric acid, sodium chloride, and dimethyl sulfoxide were purchased from FUJIFILM Wako Pure Chemical Corporation (Osaka, Japan). 1,4-Dioxane, chloroform, acetonitrile, and dimethyl sulfoxide- $d_{6}$ were purchased from Kanto Chemical, Co., Inc. (Tokyo, Japan). 2-Aminoanthracene was purchased from Sigma-Aldrich Japan, Co., LLC (Tokyo, Japan). All organic solvents and 
reagents were commercially available with guaranteed grades and used without further purification. Water was doubly distilled and deionized using a Milli-Q water system (WG222, Yamato Scientific Co., Ltd., Tokyo, Japan, and Autopure WR-600G, Merck Millipore, MA, USA) before use.

\section{Synthesis of Probe 1}

4-Carboxy-3-fluorophenylboronic acid (379 mg, $2.00 \mathrm{mmol}$ ) and pinacol (548 mg, $4.00 \mathrm{mmol}$ ) were dissolved in 1,4-dioxane $(10 \mathrm{ml})$, and the reaction mixture was stirred for $24 \mathrm{~h}$ at room temperature. 1,4-Dioxane was removed in vacuo and the residue was dissolved in a small amount of chloroform. The sample was purified by size exclusion chromatography and dried in vacuo to give a white solid (FPBAp). FPBAp (372 mg, 1.00 $\mathrm{mmol}$ ), 2-aminoanthracene (194 mg, $1.00 \mathrm{mmol}$ ), and DMT-MM (430 mg, $1.50 \mathrm{mmol})$ were dissolved in tetrahydrofuran $(20 \mathrm{ml})$ and refluxed for $24 \mathrm{~h}$. The solvent was removed in vacuo. The residue was purified by extraction (chloroform/water) and size exclusion chromatography. The obtained product was dissolved in acetonitrile-water (adjusted to $\mathrm{pH} 3$ by using hydrochloric acid) mixture $(1: 1 \mathrm{v} / \mathrm{v}, 60 \mathrm{ml})$ and the solution was stirred for $36 \mathrm{~h}$ at room temperature to remove the pinacol protection. The solution was filtered and the residue was washed with water and dried in vacuo to give a yellow-brown solid (162 mg, 0.418 mmol, 45\%). The obtained product was analyzed by ${ }^{1} \mathrm{H}$ NMR measurement, elemental analysis, and negative ESI-HRMS. ${ }^{1} \mathrm{H}$ NMR (Figure S1, $\left.300 \mathrm{MHz}, \mathrm{DMSO}-d_{6}\right)$; $\delta$ (ppm): 10.65 (s, $\left.1 \mathrm{H}\right)$, $8.63(\mathrm{~s}, 1 \mathrm{H}), 8.49(\mathrm{~d}, 2 \mathrm{H}), 8.40(\mathrm{~s}, 2 \mathrm{H}), 8.05(\mathrm{t}, 3 \mathrm{H}), 7.62-$ $7.75(\mathrm{~m}, 4 \mathrm{H}), 7.41-7.53(\mathrm{~m}, 2 \mathrm{H})$; Anal. calcd for $\mathrm{C}_{21} \mathrm{H}_{15} \mathrm{BFNO}_{3}$ (\%): C, 70.23; H, 4.21; N, 3.90; C/N, 18.0. Found: C, 70.35; H, 4.40; N, 3.95; C/N, 17.8; negative ESI-HRMS (Figure S2): $\mathrm{m} / \mathrm{z}$ calcd. for $\left[\mathrm{M}-3 \mathrm{H}+2 \mathrm{CH}_{3}\right]^{-}:$386.1364, Found: 386.1374. This peak means deprotonation $(-1 \mathrm{H})$ and methoxylation $(-2 \mathrm{OH}$ $+2 \mathrm{OCH}_{3}$ ), which was caused by ESI-MS-ionization step in methanol solvent.

\section{Evaluation of Formation of Boronic Acid Probe/CyD Supramolecular Complex}

To evaluate the formation of boronic acid probe/CyD supramolecular complex, UV-vis and fluorescence spectral measurements were performed. UV-vis and fluorescence spectra were measured in various $\mathrm{pH}$ conditions in the absence or presence of sugar $(30 \mathrm{mM})$.

\section{Evaluation of Electron-Withdrawing Effect of Boronic Acid Probe on Sugar Recognition Function}

To evaluate the fluorescence response of the $1 / \gamma$-CyD complexes toward various sugars, fluorescence spectral measurements were performed. Solutions containing $1(10 \mu \mathrm{M})$, CyD $(5 \mathrm{mM})$, sugar (0 or $30 \mathrm{mM}), \mathrm{NaCl}(100 \mathrm{mM})$, and phosphate buffer $(10 \mathrm{mM}$, adjusted to $\mathrm{pH} 7.4$ ) were prepared and fluorescence spectra were measured at $\mathrm{pH}$ 7.4. The solutions were also observed visually using UV-vis handy light.

\section{Evaluation of CD Response of Boronic Acid Probe/CyD Supramolecular Complex}

Solutions containing probe $\mathbf{1}(10 \mu \mathrm{M}), \gamma$-CyD $(5 \mathrm{mM})$, sugar $(0-$ $30 \mathrm{mM})$, phosphate buffer (10 mM, adjusted to $\mathrm{pH} 7.4)$, and $\mathrm{NaCl}$ $(100 \mathrm{mM})$ were prepared. To investigate the supramolecular complex formation of $\mathbf{1}$ and $\gamma$-CyD, CD spectra at $\mathrm{pH} 7.4$ were measured.

\section{Sugar Titration Measurements of $1 / \gamma-$ CyD Complexes}

To evaluate the sugar response of the $1 / \gamma$-CyD complexes, fluorescence spectral measurements were performed. Solutions containing probe $1(10 \mu \mathrm{M}), \gamma-\mathrm{CyD}(5 \mathrm{mM})$, sugar $(0-30 \mathrm{mM})$, phosphate buffer $(10 \mathrm{mM}$, adjusted to $\mathrm{pH} 7.4)$, and $\mathrm{NaCl}$ $(100 \mathrm{mM})$ were prepared and fluorescence spectra were measured at $\mathrm{pH} 7.4$ with the addition of sugar.

\section{RESULTS AND DISCUSSION}

\section{Evaluation of Formation of Boronic Acid Probe/CyD Supramolecular Complex}

To evaluate the function of fluorescent probe 1, the binding of 1 with sugars was confirmed by ${ }^{19}$ F NMR spectra (Figure S3). Then, UV-vis absorption spectra were measured by changing the solution $\mathrm{pH}$ (Figure S4). From $\mathrm{pH}$ profile measurements, the isosbestic point was confirmed at $323 \mathrm{~nm}$. Thus, the excitation wavelength for fluorescence measurement was set at $323 \mathrm{~nm}$. Figure 2 shows the fluorescence spectra of $\mathbf{1}$ in the presence of $\beta-\mathrm{CyD}$ or $\gamma-\mathrm{CyD}$ with various $\mathrm{pH}$. The fluorescence maximum of $\mathbf{1}$ in the presence of $\beta-\mathrm{CyD}$ was $432 \mathrm{~nm}$ and that of $\mathbf{1}$ in the presence of $\gamma$-CyD was $472 \mathrm{~nm}$. This difference in fluorescence maximum was derived from the difference in CyD cavity size (Ueno et al., 1980; Ke et al., 2009; Hashimoto et al., 2019). It is well-known that CyDs are cyclic oligosaccharides composed of glucose units $(\beta-\mathrm{CyD}$ has seven glucose units and $\gamma$-CyD has eight units). Because $\beta$ CyD has a small cavity, only one molecule of $\mathbf{1}$ could be included in its cavity. Thus, the $1 / \beta-C y D$ complexes emitted monomer fluorescence. On the other hand, $\gamma$-CyD has a larger

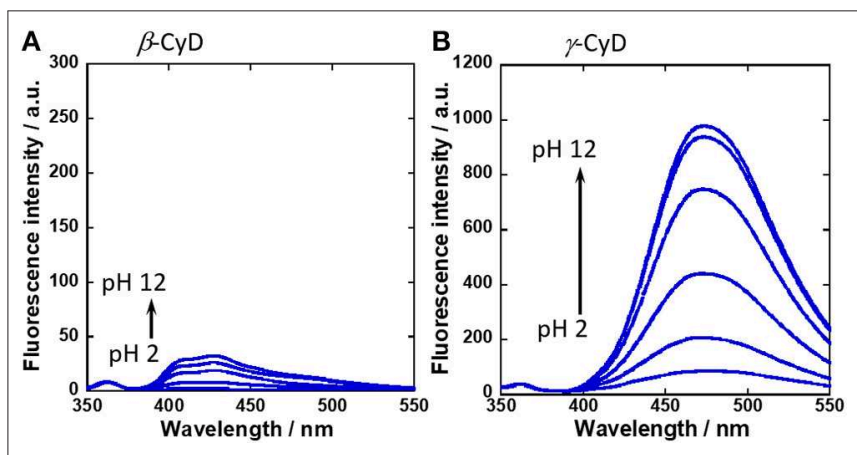

FIGURE 2 | Fluorescence spectral changes of (A) 1/ $\beta$-CyD complex with glucose and (B) $1 / \gamma$-CyD complex with glucose in $2 \%$ DMSO-98\% water (V/V) with various $\mathrm{pH}$. [1] $=10 \mu \mathrm{M},[\mathrm{CyD}]=5 \mathrm{mM}$, [glucose $]=30 \mathrm{mM},[\mathrm{NaCl}]=$ $100 \mathrm{mM}$, [phosphate buffer] $=10 \mathrm{mM}, \lambda_{\mathrm{ex}}=323 \mathrm{~nm}$. 

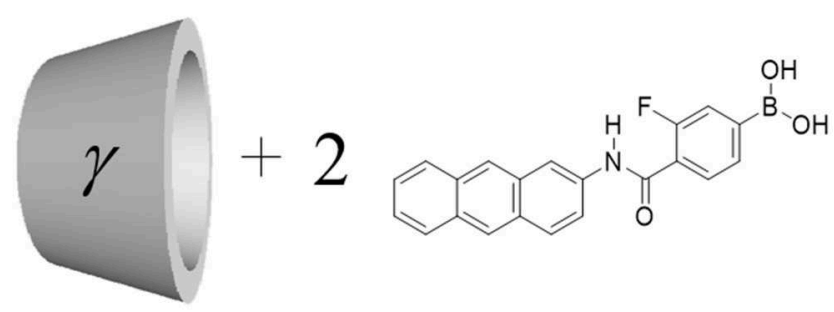
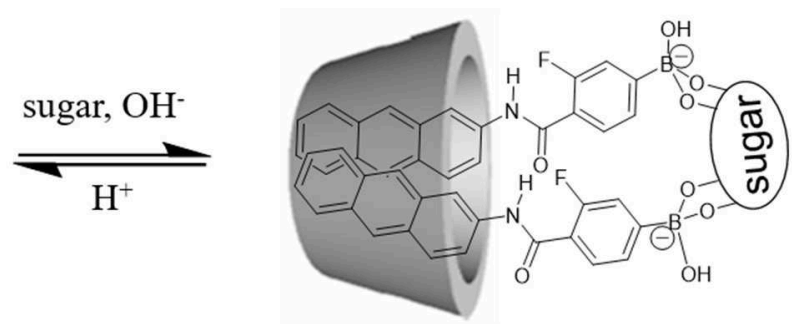

FIGURE 3 | Estimated structure of $\mathbf{1} / \gamma$-CyD complex.

cavity than $\beta-\mathrm{CyD}$, and so probe $\mathbf{1}$ and $\gamma$-CyD formed $2: 1$ complexes and emitted dimer fluorescence (Figure 3). We had previously reported that probe 2 showed similar results; $2 / \beta$ $\mathrm{CyD}$ complexes emitted monomer fluorescence and $2 / \gamma$-CyD complexes emitted dimer fluorescence (Hashimoto et al., 2019). This result indicated that the formation of a supramolecular complex was also achieved even if the probe possessed a fluorine moiety.

\section{Evaluation of Electron-Withdrawing Effect of Boronic Acid Probe on Sugar Recognition Function}

To evaluate the sugar recognition function of the $1 / \gamma-\mathrm{CyD}$ complexes, the fluorescence spectra of the $1 / \gamma$-CyD complexes in the presence of various sugars were carried out. Fluorescence intensity of the $1 / \gamma$-CyD complexes was gradually increased by addition of various sugars at basic condition (Figure 4A), similar behavior as $2 / \gamma-\mathrm{CyD}$ complexes. Moreover, $1 / \gamma-\mathrm{CyD}$ complexes emitted fluorescence by recognizing various sugars even at physiological $\mathrm{pH}$ condition. Figure $4 \mathbf{B}$ shows an optical observation image of the $1 / \gamma-C y D$ complexes in the presence of various sugars at $\mathrm{pH}$ 7.4. The fluorescence by sugar recognition could be observed by the naked eye. The $\mathrm{pH}$ profiles of the $1 / \gamma$ $\mathrm{CyD}$ complexes with other sugars were measured (Figure S5). Dimer fluorescence at $472 \mathrm{~nm}$ increased in the basic condition. The apparent $\mathrm{p} K_{\mathrm{a}}$ values of the $1 / \gamma-\mathrm{CyD}$ complexes with or without sugars were calculated by curve fitting. The $\mathrm{p} K_{\mathrm{a}}$ values of the $1 / \gamma-\mathrm{CyD}$ complexes without sugar and with glucose, fructose, and galactose were $8.57( \pm 0.05), 7.78( \pm 0.03), 7.22$ $( \pm 0.14)$, and $7.63( \pm 0.05)$, respectively. To discuss the effect of the fluorine moiety of the boronic acid probe, the $\mathrm{p} K_{\mathrm{a}}$ values of the probe were compared. The $\mathrm{p} K_{\mathrm{a}}$ values of nonfluorinated anthracene-type boronic acid probe 2 (Hashimoto et al., 2019) without sugar, with glucose and with fructose were $10.94( \pm 0.13), 10.85( \pm 0.03)$, and $9.92( \pm 0.09)$, respectively (Figure S6). Compared with probe 2, probe 1 has much lower $\mathrm{p} K_{\mathrm{a}}$ values, indicating the electron-withdrawing effect of the fluorine group of the boronic acid probes. The introduction of the fluorine moiety into the probe realized sugar recognition in the neutral $\mathrm{pH}$ condition.

To investigate the sugar recognition ability of the $1 / \gamma$ CyD complexes, the ratiometric fluorescence behavior was examined (Figure 5). Figure 5 shows the $\mathrm{pH}$ dependence of the ratio of dimer fluorescence intensity at $472 \mathrm{~nm}$ to monomer

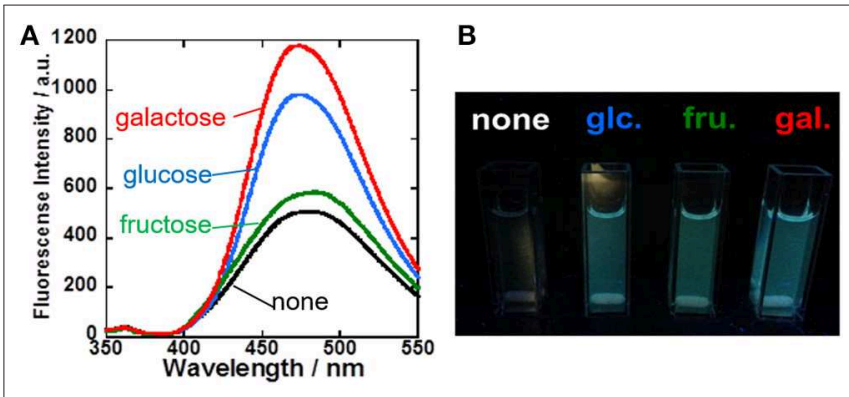

FIGURE 4 | (A) Fluorescence spectra of $\mathbf{1} / \gamma$-CyD complex with various sugars (none: black; green: fructose; blue: glucose; red: galactose) in $2 \%$ DMSO-98\% water (v/v) at basic condition around $\mathrm{pH}$ 10. [1] $=10 \mu \mathrm{M}$, $[\gamma-\mathrm{CyD}]=5 \mathrm{mM}$, [sugar $]=0$ or $30 \mathrm{mM}$, [phosphate buffer $]=10 \mathrm{mM},[\mathrm{NaCl}]=$ $100 \mathrm{mM}, \lambda_{\mathrm{ex}}=323 \mathrm{~nm}$. (B) Fluorescence image of $\mathbf{1} / \gamma$-CyD complex solution without and with $30 \mathrm{mM}$ of various sugars at $\mathrm{pH} 7.4$ under UV irradiation.
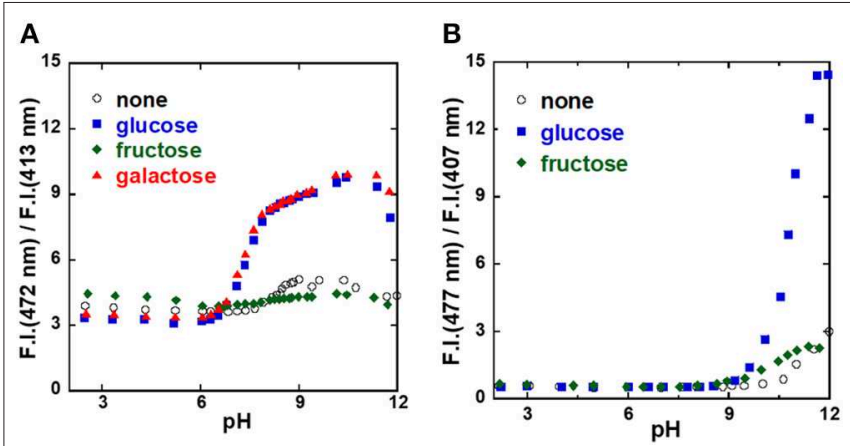

FIGURE $5 \mid \mathrm{pH}$ profiles of probe [(A) 1, (B) 2] $/ \gamma$-CyD complexes in $2 \%$ DMSO-98\% water $(\mathrm{v} / \mathrm{v})$. [probe] $=10 \mu \mathrm{M},[\gamma-\mathrm{CyD}]=5 \mathrm{mM}$, [sugar] $=0$ or $30 \mathrm{mM}$, [phosphate buffer] $=10 \mathrm{mM},[\mathrm{NaCl}]=100 \mathrm{mM}, \lambda_{\mathrm{ex}}=323 \mathrm{~nm}$.

fluorescence at $413 \mathrm{~nm}$. The ratio increased with glucose and galactose at physiological $\mathrm{pH}$, and there was almost no change in the absence of sugar or in the presence of fructose. These results indicated that the $1 / \gamma$-CyD complex formed a dimer inside the $\gamma$-CyD cavity in the presence of glucose or galactose, but not in the absence of sugar or in the presence of fructose. Thus, it is evident that the formation of the 2:1 complex of boronic acids with glucose or galactose took place inside the $\gamma$-CyD cavity. The sugar recognition ability of the $2 / \gamma$-CyD complex was investigated as well. The dimer formation of $2 / \gamma$-CyD with glucose was only noted at $\mathrm{pH} 11.5$. 


\section{Sugar Titration Measurements of $1 / \gamma-C y D$ Complexes}

To evaluate the sensitivity for sugar recognition, UV-vis and fluorescence spectral changes of the $1 / \gamma$-CyD complex at $\mathrm{pH} 7.4$ with sugar concentration were evaluated (Figures S7, S8 and Figure 6A). It was evident that dimer fluorescence increased with the addition of glucose. Figure 6B shows the dependence of the ratio of dimer fluorescence intensity at $472 \mathrm{~nm}$ to monomer fluorescence intensity at $413 \mathrm{~nm}$ on sugar concentration. The dimer/monomer ratio increased with the addition of glucose and galactose and saturated at $10 \mathrm{mM}$. In contrast, the dimer/monomer ratio remained almost constant with the addition of fructose. From the results, the binding constants of $1 / \gamma-\mathrm{CyD}$ to glucose and galactose were calculated as literature (Grynkiewicz et al., 1985; Shimpuku et al., 2009) and decided to be $1.44 \times 10^{7}$ and $1.55 \times 10^{7} \mathrm{M}^{-2}$, respectively (see Supplementary Section Calculation of the Binding Constant of $1 / \gamma$-CyD Complex
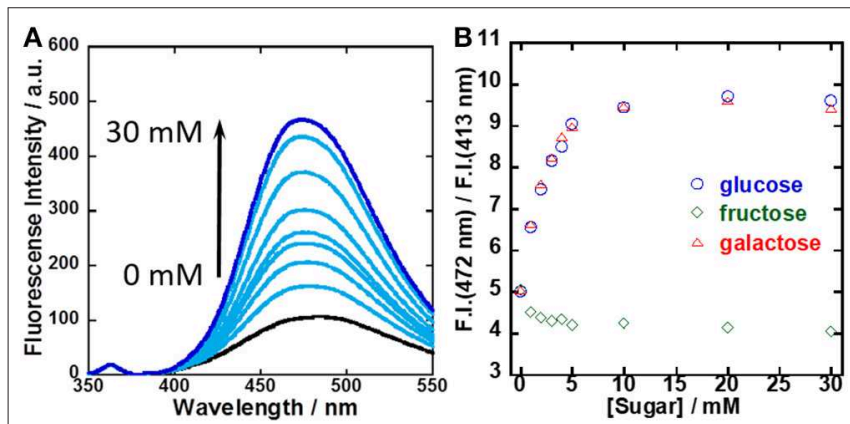

FIGURE 6 | (A) Fluorescence spectral changes of $\mathbf{1} / \gamma$-CyD complex in $2 \%$ DMSO-98\% water ( $v / v)$ at $\mathrm{pH} 7.4$ with the addition of glucose. (B) Ratiometric plots of $\mathbf{1} / \gamma$-CyD complex in 2\% DMSO-98\% water ( $/ / v)$ at $\mathrm{pH} 7.4$ with the addition of various concentrations of sugars. [1] $=10 \mu \mathrm{M},[\gamma-\mathrm{CyD}]=5 \mathrm{mM}$, $[$ sugar $]=0-30 \mathrm{mM}$, [phosphate buffer $]=10 \mathrm{mM},[\mathrm{NaCl}]=100 \mathrm{mM}, \lambda_{\mathrm{ex}}=$ $323 \mathrm{~nm}$.
With Sugar From Ratiometric Plots of Fluorescence Spectra and Figure S9).

\section{Evaluation of CD Response of Boronic Acid Probe/CyD Supramolecular Complex}

To evaluate the supramolecular complexation of probe $\mathbf{1}$ and CyD, the ICD spectra of $1 / \beta-C y D$ and $1 / \gamma-C y D$ complexes at $\mathrm{pH} 7.4$ were examined. When the boronic acid probe (guest molecule) is included in the CyD cavity, ICD and the Cotton effect are observed in the ICD spectrum. Figure S10 and Figure 7 shows the ICD spectra of the $1 / \beta-C y D$ and $1 / \gamma-C y D$ complexes with glucose, galactose, and fructose, respectively. For the $1 / \beta$ CyD complexes, weak Cotton effect due to the complexation of $\mathrm{CyD}$ and anthracene was observed (the positive Cotton effect at 200-230 $\mathrm{nm}$ with fructose are caused by the absorption of fructose itself). On the other hand, in the case of the $1 / \gamma$-CyD complex without sugar, a positive Cotton effect was observed in the shorter wavelength and a negative Cotton effect was observed in the longer wavelength. The observation of the Cotton effect indicated that probe $\mathbf{1}$ formed an inclusion complex with $\gamma$-CyD. This split-type Cotton effect denoted that two probes $\mathbf{1}$ existed as a twisted structure inside the $\gamma$-CyD cavity. In the presence of glucose (blue lines), the ICD spectra of the $1 / \gamma$-CyD complex showed reverse splitting patterns relative to the ICD spectrum of the complex without sugar (black line). However, in the presence of galactose (red lines), the ICD spectra of the $1 / \gamma$-CyD complex showed large splitting patterns. The ICD spectra of the $1 / \gamma-C y D$ complex with glucose and galactose showed strong splitting Cotton effects with the addition of sugar. The increase of the splitting indicated that complex formation of two boronic acid and one sugar molecule (glucose and galactose) fixed the twisted structure. The difference in the splitting patterns of the $1 / \gamma$-CyD complexes with glucose and galactose demonstrated the difference of the twisting rotation directions of the $1 / \gamma$-CyD-sugar complex. In the presence of fructose (green lines), the positive Cotton effect in the shorter wavelength was increased and the negative
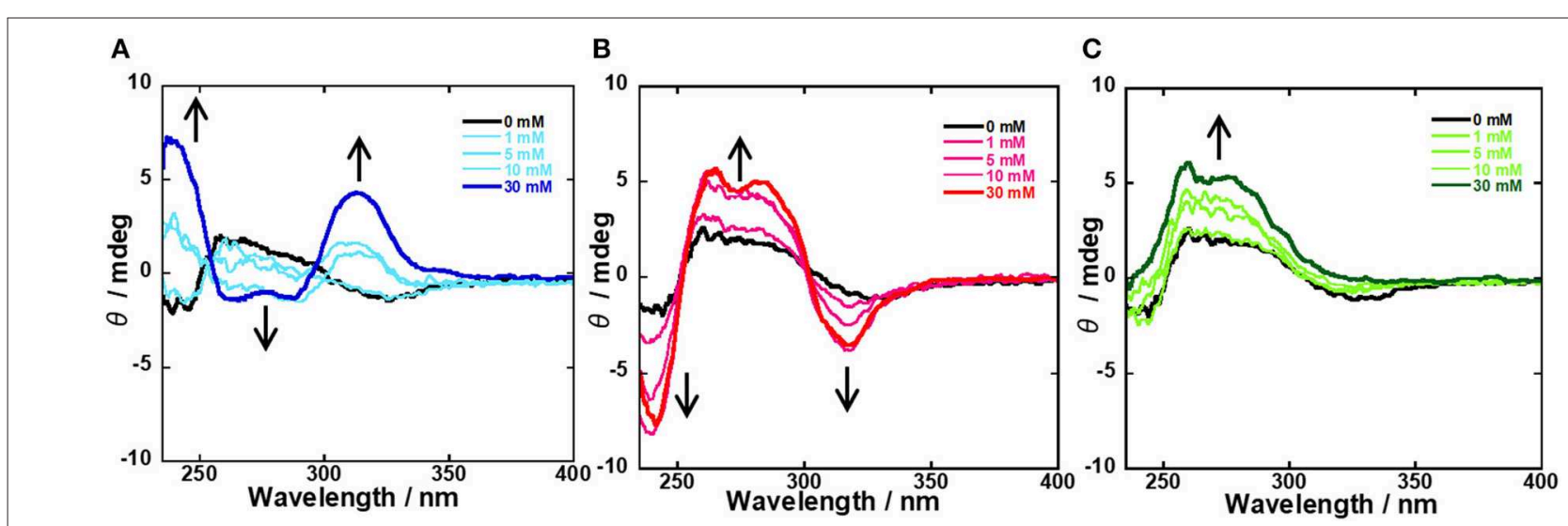

FIGURE 7 | ICD spectral changes of 1/ $\gamma$-CyD complex in 2\% DMSO-98\% water (v/v) with the addition of various concentrations of sugars [(A) glucose, (B) galactose, (C) fructose] at $\mathrm{pH}$ 7.4. [1] $=10 \mu \mathrm{M},[\gamma-\mathrm{CyD}]=5 \mathrm{mM}$, [sugar] $=0-30 \mathrm{mM}$, [phosphate buffer] $=10 \mathrm{mM}$, [NaCl] $=100 \mathrm{mM}$. 
Cotton effect in the longer wavelength disappeared with the addition of fructose. This result indicated that the formation of the twisted structure was suppressed by fructose binding. Thus, we could discriminate glucose and galactose by the splitting patterns of the ICD spectra of the $1 / \gamma$-CyD-sugar complexes. As a result, selective sugar recognition by ICD spectral analysis was achieved at physiological $\mathrm{pH}$ in $98 \%$ water-2\% DMSO solution.

\section{CONCLUSION}

We have developed a novel anthracene-type boronic acid probe possessing a fluorine moiety. By introducing the fluorine moiety into the PBA moiety, the $\mathrm{p} K_{\mathrm{a}}$ value of the boronic acid probe could be reduced from 10 to 7 . Thus, the boronic acid probe could efficiently recognize sugars at the physiological $\mathrm{pH}$ of 7.4 due to the electron-withdrawing effect of the fluorine group in the PBA moiety. Moreover, the ICD spectral response of the probe $/ \gamma$-CyD complexes to various sugars differed markedly, thereby resulting in the selective discrimination of sugars based on the splitting pattern of the Cotton effect. This fluorinated boronic acid probe is highly promising as a selective sugar recognition sensor in the neutral $\mathrm{pH}$ condition.

\section{REFERENCES}

Anslyn, E. V. (2007). Supramolecular analytical chemistry. J. Org. Chem. 72, 687-699. doi: 10.1021/jo0617971

Brewer, C. F., Miceli, M. C., and Baum, L. G. (2002). Clusters, bundles, arrays and lattices: novel mechanisms for lectin-saccharide-mediated cellular interactions. Curr. Opin. Struct. Biol. 12, 616-623. doi: 10.1016/S0959-440X(02)00364-0

Brodesser, S., Sawatzki, P., and Kolter, T. (2003). Bioorganic chemistry of ceramide. Eur. J. Org. Chem. 2003, 2021-2034. doi: 10.1002/ejoc.200200518

Davis, B. G. (2002). Synthesis of glycoproteins. Chem. Rev. 102, 579-601. doi: $10.1021 / \mathrm{cr} 0004310$

Deorea, B., and Freund, M. S. (2003). Saccharide imprinting of poly(aniline boronic acid) in the presence of fluoride. Analyst 128, 803-806. doi: 10.1039/b300629h

Egawa, Y., Gotoh, R., Niina, S., and Anzai, J. (2007). Ortho-azo substituted phenylboronic acids for colorimetric sugar sensors. Bioorg. Med. Chem. Lett. 17, 3789-3792. doi: 10.1016/j.bmcl.2007.02.073

Egawa, Y., Gotoh, R., Seki, T., and Anzai, J. (2009). Sugar response of boronic acidsubstituted azobenzene dye-modified polymer. Mater. Sci. Eng. C 29, 115-118. doi: 10.1016/j.msec.2008.05.014

Ekanayake, E. M., Preethichandra, D. M., and Kaneto, K. (2007). Polypyrrole nanotube array sensor for enhanced adsorption of glucose oxidase in glucose biosensors. Biosens. Bioelectron. 23, 107-113. doi: 10.1016/j.bios.2007.03.022

Endo, H., Yonemori, Y., Musiya, K., Maita, M., Shibuya, T., Ren, H., et al. (2006). A needle-type optical enzyme sensor system for determining glucose levels in fish blood. Anal. Chim. Acta 573, 117-124. doi: 10.1016/j.aca.2006.04.068

Fujita, N., Shinkai, S., and James, T. D. (2008). Boronic acids in molecular self-assembly. Chem. Asian J. 3, 1076-1091. doi: 10.1002/asia.200800069

Grynkiewicz, G., Poenie, M., and Tsien, R. Y. (1985). A new generation of $\mathrm{Ca}^{2+}$ indicators with greatly improved fluorescence properties. J. Biol. Chem. 260, 3440-3450.

Hashimoto, T., Kumai, M., Maeda, M., Miyoshi, K., Tsuchido, Y., Fujiwara, S., et al. (2019). Structural effect of fluorophore on phenylboronic acid fluorophore/cyclodextrin complex for selective glucose recognition. Front. Chem. Sci. Eng. doi: 10.1007/s11705-019-1851-y. [Epub ahead of print].

\section{DATA AVAILABILITY STATEMENT}

All datasets generated for this study are included in the article/Supplementary Material.

\section{AUTHOR CONTRIBUTIONS}

KS, CK, and MC performed the experiments. KS, YT, THas, and THay wrote the manuscript. All authors designed the experiments and were involved in the data analysis. All authors designed the experiments, were involved in the data analysis, and have expressed approval of the final version of the manuscript.

\section{FUNDING}

This work was financially supported by JSPS KAKENHI Grant Numbers JP26248038, JP18K05180, and JP18K14255, and the funding from the Private University Research Branding Project.

\section{SUPPLEMENTARY MATERIAL}

The Supplementary Material for this article can be found online at: https://www.frontiersin.org/articles/10.3389/fchem. 2019.00806/full\#supplementary-material

Iwami, Y., Yokozawa, T., Yamamoto, H., and Kanekiyo, Y. (2015). Boronic acidbased thin films that show saccharide-responsive multicolor changes. Inc. J. Appl. Polym. Sci. 132:42679. doi: 10.1002/app.42679

James, T. D., Sandanayake, K. R. A. S., and Shinkai, S. (1994). A glucoseselective molecular fluorescence sensor. Angew. Chem. Int. Ed. 33, 2207-2209. doi: 10.1002/anie.199422071

James, T. D., Sandanayake, K. R. A. S., and Shinkai, S. (1996). Saccharide sensing with molecular receptors based on boronic acid. Angew. Chem. Int. Ed. 35, 1910-1922. doi: 10.1002/anie.199619101

Jin, S., Cheng, Y., Reid, S., Li, M., and Wang, B. (2010). Carbohydrate recognition by boronolectins, small molecules, and lectins. Med. Res. Rev. 30, 171-257. doi: 10.1002/med.20155

Kameta, N., and Hiratani, K. (2006). Fluorescence-responsive $\mathrm{H}_{2} \mathrm{PO}_{4}^{-}$ receptor based on macrocyclic boron complex. Chem. Lett. 35, 536-537. doi: $10.1246 / \mathrm{cl} .2006 .536$

Kanekiyo, Y., and Hiraoki, T. (2005). Selective glucose sensing utilizing complexation with fluorescent boronic acid on polycation. Chem. Lett. 34, 196-197. doi: 10.1246/cl.2005.196

Kanekiyo, Y., and Tao, H. (2006). Glucose-specific sensing with boronic acid utilizing enzymatic oxidation. Chem. Lett. 35, 852-853. doi: $10.1246 / \mathrm{cl} .2006 .852$

Kano, H., Tanoue, D., Shimaoka, H., Katano, K., Hashimoto, T., Kunugita, H., et al. (2014). Effects of cyclodextrins on intramolecular photoinduced electron transfer in a boronic acid fluorophore. Anal. Sci. 30, 643-648. doi: 10.2116/analsci.30.643

Ke, C., Yang, C., Mori, T., Wada, T., Liu, y., and Inoue, Y. (2009). Catalytic enantiodifferentiating photocyclodimerization of 2-anthracenecarboxylic acid mediated by a non-sensitizing chiral metallosupramolecular host. Angew. Chem. Int. Ed. 48, 6675-6677. doi: 10.1002/anie.200902911

Kumai, M., Kozuka, S., Samizo, M., Hashimoto, T., Suzuki, I., and Hayashita, T. (2012). Glucose recognition by a supramolecular complex of boronic acid fluorophore with boronic acid-modified cyclodextrin in water. Anal. Sci. 28, 121-126. doi: 10.2116/analsci.28.121

Matsumoto, A., Matsumoto, H., Maeda, Y., and Miyahara, Y. (2013). Simple and robust strategy for potentiometric detection of glucose using fluorinated 
phenylboronic acid self-assembled monolayer. Biochim. Biophys. Acta 1830, 4359-4364. doi: 10.1016/j.bbagen.2013.03.004

Minami, T., Minamiki, T., Hashima, Y., Yokoyama, D., Sekine, T., Fukuda, K., et al. (2014). An extended-gate type organic field effect transistor functionalized by phenylboronic acid for saccharide detection in water. Chem. Commun. 50, 15613-15615. doi: 10.1039/C4CC07498J

Nishiyabu, R., Tomura, M., Okade, T., and Kubo, Y. (2018). Boronic acids as molecular inks for surface functionalization of polyvinyl alcohol substrates. New J. Chem. 42, 7392-7398. doi: 10.1039/C8NJ00992A

Ohtsubo, K., and Marth, J. D. (2006). Glycosylation in cellular mechanisms of health and disease. Cell 126, 855-867. doi: 10.1016/j.cell.2006.08.019

Ozawa, R., Hashimoto, T., Yamauchi, A., Suzuki, I., Smith, B. D., and Hayashita, T, (2008). Effect of cyclodextrins and saccharide sensing function of a fluorescent phenylboronic acid in water. Anal. Sci. 24, 207-212. doi: 10.2116/analsci.24.207

Shimomura, N., Egawa, Y., Miki, R., Fujihara, T., Ishimaru, Y., and Seki, T. (2016). A red fluorophore comprising a borinate-containing xanthene analogue as a polyol sensor. Org. Biomol. Chem. 14, 10031-10036. doi: 10.1039/C6OB01695B

Shimpuku, C., Ozawa, R., Sasaki, A., Sato, F., Hashimoto, T., Yamauchi, A., et al. (2009). Selective glucose recognition by boronic acid azoprobe/ $\gamma$-cyclodextrin complexes in water. Chem. Commun. 13, 1709-1710. doi: 10.1039/b819938h

Shoji, E., and Freund, M. S. (2002). Potentiometric saccharide detection based on the $\mathrm{p} K_{\mathrm{a}}$ changes of poly(aniline boronic acid). J. Am. Chem. Soc. 124, 12486-12493. doi: $10.1021 /$ ja0267371

Sierra, J. F., Galbán, J., and Castillo, J. R. (1997). Determination of glucose in blood based on the intrinsic fluorescence of glucose oxidase. Anal. Chem. 69, 1471-1476. doi: 10.1021/ac9611327

Soma, S., Suzuki, T., Bekele, T. G., Tsuchido, Y., Hashimoto, T., and Hayashita, T. (2018). Design of saccharide recognition material based on boronic acid fluorophore/cyclodextrin gel. J. Ion Exch. 29, 126-130. doi: 10.5182/jaie.29.126

Sun, X., and James, T. D. (2015). Glucose sensing in supramolecular chemistry. Chem. Rev. 115, 8001-8037. doi: 10.1021/cr500562m

Tsuchido, Y., Fujiwara, S., Hashimoto, T., and Hayashita, T. (2017). Development of supramolecular saccharide sensors based on cyclodextrin complexes and self-assembling systems. Chem. Pharm. Bull. 65, 318-325. doi: 10.1248/cpb.c16-00963

Tsuchido, Y., Sakai, Y., Aimu, K., Hashimoto, T., Akiyoshi, K., and Hayashita, T. (2015). The design of phenylboronic acid azoprobe/polyamidoamine dendrimer complexes as a supramolecular sensor for saccharide recognition in water. New J. Chem. 39, 2620-2626. doi: 10.1039/C4NJ01309C
Tsuchido, Y., Sato, R., Nodomi, N., Hashimoto, T., Akiyoshi, K., and Hayashita, T. (2016). Saccharide recognition based on self-assembly of amphiphilic phenylboronic acid azoprobes. Langmuir 32, 10761-10766. doi: 10.1021/acs.langmuir.6b02917

Ueno, A., Takahashi, K., and Osa, T. (1980). One host-two guests complexation between $\gamma$-cyclodextrin and sodium $\alpha$-naphthylacetate as shown by excimer fluorescence. J. Chem. Soc. Chem. Commun. 19, 921-922. doi: $10.1039 /$ C39800000921

White, B. J., and Harmon, H. J. (2002). Novel optical solid-state glucose sensor using immobilized glucose oxidase. Biochem. Biophys. Res. Commun. 296, 1069-1071. doi: 10.1016/S0006-291X(02)02051-X

Wu, X., Chen, X.-X., and Jiang, Y.-B. (2017). Recent advances in boronic acid-based optical chemosensors. Analyst 142, 1403-1414. doi: 10.1039/C7AN00439G

Wu, X., Chen, X.-X., Zhang, M., Li, Z., Gale, P. A., and Jiang, Y.B. (2016). Self-assembly of a "double dynamic covalent" amphiphile featuring a glucose-responsive imine bond. Chem. Commun. 52, 6981-6984. doi: 10.1039/C6CC03167F

Xu, X.-D., Cheng, H., Chen, W.-H., Cheng, S.-X., Zhuo, R.-X., and Zhang, X.Z. (2013). In situ recognition of cell-surface glycans and targeted imaging of cancer cells. Sci. Rep. 3:2679. doi: 10.1038/srep02679

Ye, G., Li, X., and Wang, X. (2010). Diffraction grating of hydrogel functionalized with glucose oxidase for glucose detection. Chem. Commun. 46, 3872-3874. doi: $10.1039 / \mathrm{c} 002429 \mathrm{e}$

Zhai, W., Sun, X., James, T. D., and Fossey, J. S. (2015). Boronic acid-based carbohydrate sensing. Chem. Asian J. 10, 1836-1848. doi: 10.1002/asia.201500444

Conflict of Interest: The authors declare that the research was conducted in the absence of any commercial or financial relationships that could be construed as a potential conflict of interest.

Copyright $\odot 2019$ Sugita, Tsuchido, Kasahara, Casulli, Fujiwara, Hashimoto and Hayashita. This is an open-access article distributed under the terms of the Creative Commons Attribution License (CC BY). The use, distribution or reproduction in other forums is permitted, provided the original author(s) and the copyright owner(s) are credited and that the original publication in this journal is cited, in accordance with accepted academic practice. No use, distribution or reproduction is permitted which does not comply with these terms. 